\title{
Clinical correlation between Child Pugh's score and oesophageal varices in upper gastrointestinal endoscopy in cirrhotic patient
}

\section{Thapa PB', Maharjan DK², Tamang $\mathrm{TY}^{3}$, Shrestha $\mathrm{SK}^{4}$}

${ }^{1}$ Prabin BikramThapa, Associate Professor; ${ }^{2}$ Dhiresh Kumar Maharjan, Lecturer; ${ }^{3}$ Tseten Yonjon Tamang, Lecturer; ${ }^{4}$ Suman Kumar Shrestha, Associate Professor; Department of Surgery, Kathmandu Medical College Teaching Hospital, Kathmandu, Nepal

\begin{abstract}
Background: Bleeding oesophageal varices are a major complication of portal hypertension following liver cirrhosis. Child Pugh's score has been used as a prognostic tool while managing a patient with liver cirrhosis.

Objective: To clinically correlate Child Pugh's score and oesophageal varices in upper gastrointestinal endoscopy in cirrhotic patient.

Methods: This is a prospective descriptive study done from January 2014 to January 2015. Cirrhotic patients who were referred for upper gastrointestinal endoscopy with or without history of upper $\mathrm{Gl}$ bleeding were included. Patients were categorized according to Child Pugh's score into A, B, C and correlated with their endoscopic finding of grading of varices. Results: A total of 50 cirrhotic patients underwent upper gastrointestinal endoscopy during one year. Out of which $60 \%$ were in Child Pugh's category A, $30 \%$ in category B and $10 \%$ in category C. Among them $62 \%$ had grade I varices, $20 \%$ had grade II varices and $18 \%$ had grade III varices. Those who presented with history of hematemesis had higher grades of oesophageal varices in comparison to those without hematemesis.

Conclusion: Cirrhotic patients with higher Child Pugh's score had higher grades of oesophageal varices leading presentation with hematemesis. Hence, routine screening of cirrhotic patient is necessary before the development of varices.
\end{abstract}

Key words: Child Pugh's score, Cirrhosis, Oesophageal varices

\section{INTRODUCTION}

Pleeding oesophageal varices are a major 3 complication of portal hypertension following liver cirrhosis. Portal hypertension develops in cirrhosis because of an increase in splanchnic blood flow secondary to vasodilation within the splanchnic vascular bed and because of increased resistance to the passage of blood through the liver'. Child Pugh grading correlates with presence of gastro-esophagealvarices as $40 \%$ of Child Pugh A patients have varices while they are present in $85 \%$ of Child Pugh C patients ${ }^{2}$. The mortality of an episode of variceal bleeding varies from 30\% - 50\% depending on the Child Pugh grade and co-morbidities ${ }^{3,4}$. Endoscopic band ligation (EBL) is

Address for correspondence

Dr. Prabin Bikram Thapa

Associate Professor, Department of Surgery

Kathmandu Medical College Teaching Hospital

Sinamangal, Kathmandu, Nepal

Email: prabinbt@gmail.com the treatment of choice for acute variceal bleeding. It is also performed for primary and secondary prophylaxis of bleeding from oesophageal varices ${ }^{5-8}$.

Hence, our objective is to clinically correlate Child Pugh's score of these cirrhotic patients referred for endoscopy with grade of oesophageal varices in terms of history of hematemesis.

\section{METHODS}

This was a prospective cross sectional descriptive observational study conducted from January 2014 to January 2015 in Unit III, department of Surgery, Kathmandu Medical College Teaching Hospital (KMCTH), Sinamangal, Nepal. Ethical clearance for the study was obtained from the Institutional Review Committee at KMCTH.

Only diagnosed cirrhotic patients on history, clinical examinations, haematological and radiological 
investigations referred from department of Medicine for upper gastrointestinal (Gl) endoscopy were included in thisstudy. Haemodynamically unstable cirrhotic patients with hematemesis were excluded.

Informed consent was obtained from the stable patients. Consent was taken from the spouse/parents or immediate close relative in situations where the patient was unable to give consent.

Cirrhotic patients were categorized according to Child Pugh's score ${ }^{9}$. The score employs five clinical measures of liver disease as in table 1. The cirrhosis class is based on the total score the prognosis is directly related to the score (table 2):

Class A: Total score 5 or 6

Class B: Total score 7-9

Class C: Total score 10 or higher

\section{ENDOSCOPIC PROCEDURE:}

Oesophageal varices were graded as absent, grade 1, 2 and 3 according to De Franchisetal ${ }^{11}$ :

Grade 1: Oesophageal varices occupied less than a third of the lumen and flatten with air insufflation.

Grade 2: Oesophageal varices occupied less than a third and did not flatten with air insufflation.
Grade 3: Oesophageal varices occupied at least a third of the lumen and did not flatten with air insufflation.

Oesophageal variceal haemorrhage was diagnosed by:

- Presence of hematemesis or coffee ground vomitus and melena

- Signs of active bleeding on endoscopy, adherent clots, erosions on varices and white nipple signs

- Red-colour sign over large varices without other bleeding sources.

Endoscopic variceal ligation was performed in patient with grade II (medium) and grade III (large) using Saeed's six-shooter multiband ligator (Cook Medical Inc., Bloomington, IN, USA). Around six bands or less were applied in a single session.

As a part of post endoscopic therapy, patients were kept nil per oral and on intravenous fluids for at least 24 hours.

Descriptive statistics of mean, standard deviation, percentage were obtained from the data. Statistical analysis was by SPSS statistical package version 10.1.

\section{RESULTS}

A total of 845 patients underwent upper $\mathrm{Gl}$ endoscopy in the study period. Among them, 50 patients with diagnosis of cirrhosis, referred from the department of Medicine were included.Those who presented with history of hematemesis had higher grades of oesophageal varices in comparison to those without hematemesis.

Table 1: Child Pugh's score system ${ }^{10}$

\begin{tabular}{lccc}
\hline Measure & $\mathbf{1}$ point & $\mathbf{2}$ points & $\mathbf{3}$ points \\
Total bilirubin, $\mu \mathrm{mol} / \mathrm{l}(\mathrm{mg} / \mathrm{dl})$ & $<34(<2)$ & $34-50(2-3)$ & $>50(>3)$ \\
Serum albumin $(\mathrm{g} / \mathrm{dl})$ & $>3.5$ & $2.8-3.5$ & $<2.8$ \\
Prothrombin time, prolongation $(\mathrm{sec})$ & $<4.0$ & $4.0-6.0$ & $>6.0$ \\
Ascites & None & Mild & Moderate to Severe \\
Hepatic encephalopathy & None & $\begin{array}{c}\text { Grade I-II (or suppressed } \\
\text { with medication) }\end{array}$ & $\begin{array}{c}\text { Grade III-IV (or } \\
\text { refractory) }\end{array}$ \\
\hline
\end{tabular}

Table 2: Prognostic indicator of Child Pugh's score

\begin{tabular}{cccc}
\hline Points & Class & One year survival & Two years survival \\
$5-6$ & A & $100 \%$ & $85 \%$ \\
$7-9$ & B & $81 \%$ & $57 \%$ \\
$10-15$ & C & $45 \%$ \\
\hline
\end{tabular}


Table 3: Demographic representation

\begin{tabular}{|c|c|}
\hline Mean age \pm SD & $41.4 \pm 11.7$ years \\
\hline M:F ratio & $43: 7$ (86\% vs. $14 \%)$ \\
\hline \multirow[t]{3}{*}{ Child Pugh's score } & A: $30(60 \%)$ \\
\hline & B: 15 (30\%) \\
\hline & C: 5 (10\%) \\
\hline \multirow{3}{*}{ Grading of oesophageal varices } & Grade I: 31 (62\%) \\
\hline & Grade II: 10 (20\%) \\
\hline & Grade III: 9 (18\%) \\
\hline
\end{tabular}

Table 4: Child Pugh's score and grading of oesophageal varices in relation with history of hematemesis

\begin{tabular}{|c|c|c|c|c|c|}
\hline \multirow[t]{2}{*}{ History } & \multirow[t]{2}{*}{ Child Pugh's score } & \multicolumn{3}{|c|}{ Oesophageal Varices } & \multirow[t]{2}{*}{ Total } \\
\hline & & Grade I & Grade II & Grade III & \\
\hline \multirow{3}{*}{$\begin{array}{l}\text { Without history of } \\
\text { hematemesis }\end{array}$} & $A$ & 24 & 0 & & 24 \\
\hline & $B$ & 0 & 1 & & 1 \\
\hline & Total & 24 & 1 & & 25 \\
\hline \multirow{4}{*}{ With history of Hematemesis } & $A$ & 6 & 0 & 0 & 6 \\
\hline & B & 1 & 9 & 4 & 14 \\
\hline & $\mathrm{C}$ & 0 & 0 & 5 & 5 \\
\hline & Total & 7 & 9 & 9 & 25 \\
\hline
\end{tabular}

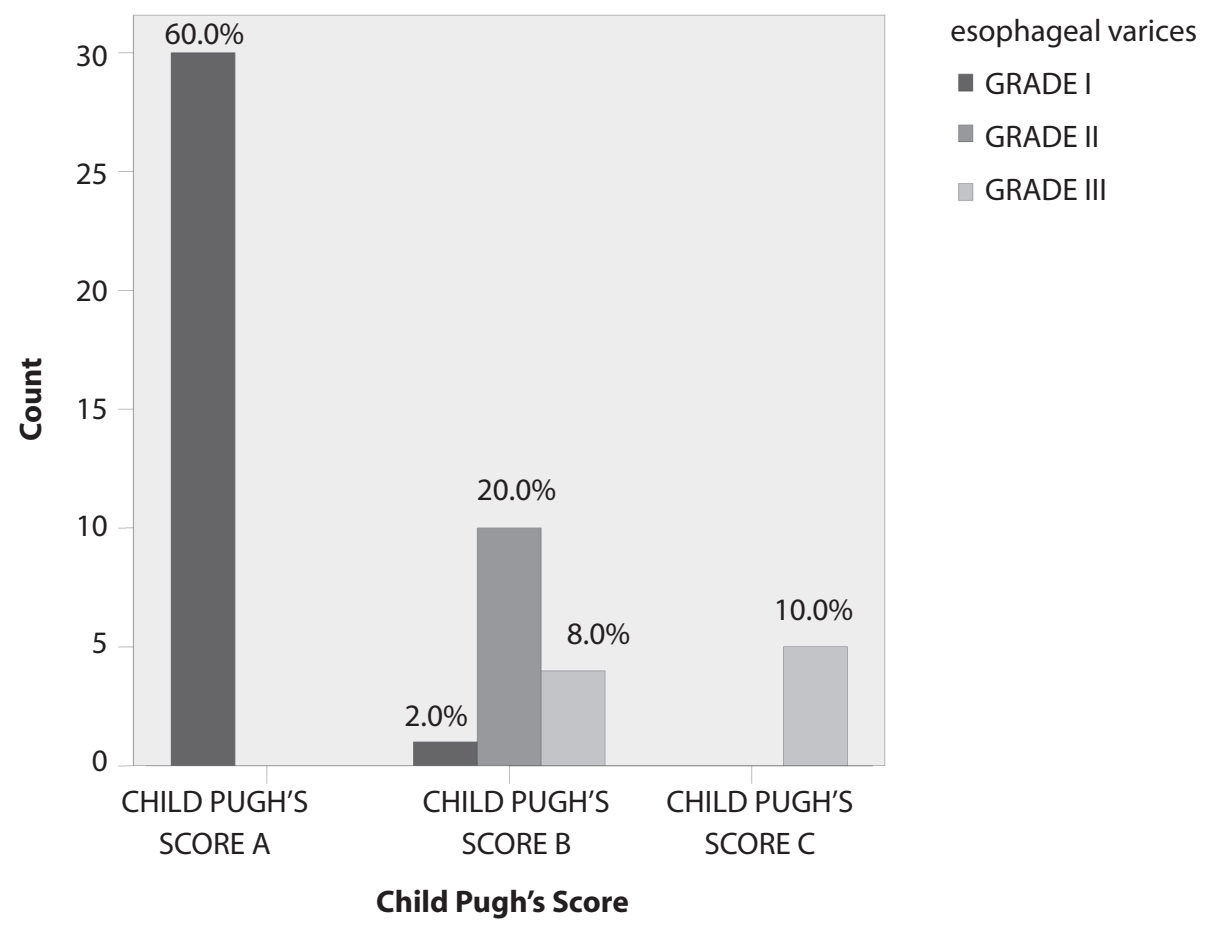




\section{DISCUSSION}

Esophagogastroduodenoscopy (EGD) is generally indicated for the management of patients admitted to intensive care units (ICUs) with upper gastrointestinal (GI) haemorrhage. In our study, patient with high grade of Child Pugh's score had higher grade of oesophageal varices.Our result was similar with Sumon SM et al where they had similar correlation between Child Pugh's score where grade $B$ and $C$ were associated with higher grade of varices ${ }^{12}$.

However, the relationship between Child Pugh score and oesophageal varices is not consistent. Some studies fail to show a relationship between oesophageal varices and Child Pugh score ${ }^{13-15}$. Hence, parameters like platelet count and white cell count have been used to predict the presence of significant oesophageal varices and therefore increase the yield of endoscopy ${ }^{16-18}$.

The prevalence of oesophageal varices in cirrhosis is estimated at 9-36\% ${ }^{19-22}$.Variceal bleeding in cirrhotic patients is associated with high morbidity and mortality. Primary prophylaxis can reduce the risk of bleeding. Hence, all cirrhotic patients should undergo endoscopy to detect varices. If significant oesophageal varices are found (grade 2 and above), a beta blocker or endoscopic variceal ligation are effective prophylactic measures.

Study done by Cales et al ${ }^{23}$ has shown that after univariate analysis, a longer duration of cirrhosis and grade 1 oesophageal varices at entry were predictive factors for the occurrence of large oesophageal varices, whereas, multivariate analysis showed that the initial size of the oesophageal varices, a high initial Child Pugh score, and a smaller improvement in Child Pugh score during the study were independent risk factors. Among patients with grade 0 and 1 oesophageal varices at the start of the study, the proportions with large oesophageal varices at two years were $31 \%$ and $70 \%$ respectively.

In a study done by Chalasani $\mathrm{N}$ et al in screening process of cirrhotic patients who had no variceal bleeding before, had the prevalence of large oesophageal varices of $20 \%$. In their study, patients with a platelet count of $\geq 88,000$ / $\mathrm{mm}^{3}$ and no splenomegaly by physical examination had a risk of large oesophageal varices of $7.2 \%$ where as those with splenomegaly or platelet count $<88,000$ / $\mathrm{mm}^{3}$ had a risk of large oesophageal varices of $28 \%(\mathrm{p}<$ 0.0001 ). Hence, they recommend for stratifying with clinical parameters for use of upper Gl endoscopy as a screening tool. However, limitation of this study was observational descriptive with small study sample.

\section{CONCLUSION}

Cirrhotic patients with higher Child Pugh's score had higher grades of oesophageal varices leading presentation with hematemesis. Hence, routine screening of cirrhotic patient is necessary before the development of varices.

\section{REFERENCES}

1. Gupta TK, ChenL, GroszmannRJ. Pathophysiology of portal hypertension. Clin Liver Dis.1997; 11-2.

2. Pagliaro L, D’Amico G, Pasta L, Politi F, Vizzini G, Traina $M$, et al. Portal hypertension in cirrhosis: Natural history. Oxford, UK: Blackwell Scientific, 1994: 72-92.

3. Chalasani N, Kahi C, Francois F, Pinto A, Marathe A, Bini EJ, et al. Improved patient survival after acute variceal bleeding: a multicenter, cohort study. The American J of Gastroenterol. 2003;98(3):653-9.

4. Graham DY, Smith JL. The course of patients after variceal hemorrhage. Gastroenterology. 1981;80(4):800-9.

5. Bonilha DQ, Lenz L, Correia LM, Rodrigues RA, de Paulo GA, Ferrari AP, et al. Propranolol associated withendoscopic band ligation reduces recurrence of esophageal varices for primary prophylaxis of variceal bleeding: a randomized controlled trial.Eur J GastroenterolHepatol. 2015; 27(1):84-90.

6. Albillos A, Tejedor M. Secondary prophylaxis for esophageal variceal bleeding. Clin Liver Dis. 2014; 18(2):359-70.

7. Ji JS, Cho YS. Endoscopic band ligation: beyond prevention and management of gastroesophageal varices. World J Gastroenterol. 2013 Jul 21; 19(27):4271-6.

8. Poza CJ, Froilan TC, Burgos GA, Gea RF, Suárez de PJM.Endoscopic management of esophageal varices. World J GastrointestEndosc. 2012 Jul $16 ; 4(7): 312-22$

9. Lee JY, Lee JH, Kim SJ, Choi DR, Kim KH, Kim YB, et al. Comparison of predictive factors related to the mortality and rebleeding caused by variceal bleeding: Child-Pugh score, MELD score, and Rockall score. The Korean journal of Hepatology. 2002;8(4):458-64.

10. Pugh RNH, Murray-Lyon IM, Dawson $J$, et al. Transection of the oesophagus for bleeding oesophagealvarices. Br J Surg. 1973; 60: 646-9. 
11. deFranchis $R$, Primignani $M$. Why do varices bleed? Gastroenterology clinics of North America. 1992;21(1):85-101.

12. Sumon SM, Sutradhar SR, Chowdhury M, Khan NA, Uddin MZ, Hasan MI et al. Relation of different grades of esophageal varices with Child-Pugh classes in cirrhosis of liver. MMJ 2013;22(1):37-41.

13. Chalasani N, Kahi C, Francois F, Pinto A, Marathe A, Bini EJ, et al. Model for end-stage liver disease (MELD) for predicting mortality in patients with acute variceal bleeding. Hepatology. 2002;35(5):1282-4

14. Benedeto-Stojanov D, Nagorni A, Bjelakovic G, Stojanov D, Mladenovic B, Djenic N. The Model for the End-Stage Liver Disease and Child-Pugh score in predicting prognosis in patients with liver cirrhosis and esophageal variceal bleeding.Vojnosanit Pregl. 2009;66(9):724-8.

15. Flores-Rendon AR, Gonzalez-Gonzalez JA, GarciaCompean D, Maldonado-Garza HJ, Garza-Galindo $A A$. Model for end stage of liver disease (MELD) is better than the Child-Pugh score for predicting inhospital mortality related to esophageal variceal bleeding. Ann Hepatol. 2008;7(3):230-4.

16. Gana JC, Turner D, Mieli VG, Davenport M,Miloh T, Avitzur $Y$ et al.A clinical prediction rule and platelet count predictesophageal varices in children. Gastroenterology 2011;141(6):2009-16.

17. Chalasani N, Imperiale TF, Ismail A, Sood G, Carey M, Wilcox CMet al.Predictors of large esophageal varices in patients with cirrhosis. The American J of Gastroenterol1999;94(11):3285-91
18. Qamar AA, Grace ND, Groszmann RJ, Garcia TG, Bosch J, Burroughs AK et al. Incidence, prevalence, and clinical significance of abnormal hematologic indices in compensated cirrhosis. Clinical Gastroenterologyand Hepatology.2009;7(6):689-95.

19. Merli M, Nicolini G, Angeloni S, Rinaldi V, De Santis A, Merkel $C$ et al. Incidence and natural history of small esophageal varices in cirrhotic patients. Journal of Hepatology.2003; 38(3):266-72.

20. Jensen DM. Endoscopic screening for varices in cirrhosis: findings, implications, and outcomes. Gastroenterology.2002; 122(6):1620-30.

21. Sarin SK, Lahoti D, Saxena SP, Murthy NS, Makwana UK. Prevalence, classification and natural history of gastric varices: a long-term follow-up study in 568 portal hypertension patients. Hepatology.1992; 16(6):1343-9.

22. Madhotra R, Mulcahy HE, Willner I, Reuben A. Prediction of esophageal varices in patients with cirrhosis. J of clinical Gastroenterol.2002; 34(1):81-5.

23. Cherian JV, Deepak N, Ponnusamy $\mathrm{RP}$, Somasundaram A, Jayanthi V. Non-invasive predictors of esophageal varices. Saudi J Gastroenterol. 2011;17(1):64-8.

24. Cales $P$, Desmorat $H$, Vinel JP, Caucanas JP, RavaudA,Gerin $P$ et al. Incidence of large oesophagealvarices in patients with cirrhosis: application to prophylaxis of first bleeding. Gut 1990; 31(11):1298-1302. 